\title{
Téoros
}

Revue de recherche en tourisme

\section{Une industrie à mieux connaître}

\section{Pierre Labrie}

Volume 4, numéro 3, novembre 1985

L'essor de l'industrie des congrès

URI : https://id.erudit.org/iderudit/1080782ar

DOI : https://doi.org/10.7202/1080782ar

Aller au sommaire du numéro

\section{Éditeur(s)}

Université du Québec à Montréal

\section{ISSN}

0712-8657 (imprimé)

1923-2705 (numérique)

Découvrir la revue

Citer ce document

Labrie, P. (1985). Une industrie à mieux connaître. Téoros, 4(3), 1-1.

https://doi.org/10.7202/1080782ar d'utilisation que vous pouvez consulter en ligne.

https://apropos.erudit.org/fr/usagers/politique-dutilisation/ 


\section{Présentation}

\section{Une industrie à mieux connaître}

Les congrès constituent une part importante de l'activité économique associée au tourisme. Ces événements sont générateurs de clientèles, de dépenses de consommation et motivent, dans bien des cas, d'importants investissements immobihers (centre de congrès, hôtels, etc.).

Bien que cette "industrie" occupe une place de choix dans la réalité commerciale de l'industrie touristique québécoise, elle est trop souvent ignorée quand c'est le temps d'étudier à fond divers aspects du phénomène "tourisme".

Elle souffre d'être associée trop étroitement à un secteur d'activités, I'hòtellerie, alors qu'elle touche, en réalité, a tous les aspects du tourisme.

I/ faut admettre qu'il existe en Amérique du Nord de nombreuses publications spécialisées et de nombreuses recherches et études sur l'industrie des congrès. Leur accessibilité est, toutefois, limitée aux initiés, i.e. ceux qui ont eu le privilege d'apprendre sur le tas, dans le cadre d'une expérience professionnelle, les us et coutumes de cette industrie.

Les programmes de formation ignorent souvent l'étude de cette industrie et $n$ "amenent pas les jeunes professionnels à une prise de conscience du phénomène congrès et des règles du jeu qui le gouvernent.

Ce numéro de Téoros se veut une contribution à une meilleure connaissance de l'offre québécoise et des intervenants qui en façonnent le développement. Il est en quelque sorte le complément et la continuité d'autres textes publiés dernièrement au Québec, notamment dans la revue $\mathbf{M B A}$ (juin 1985) et dans le journal Finance (février (1985).

Fait important à souligner, la plupart des auteurs invités à réfléchir sur cette question sont, dans le quotidien, impliqués á fond dans des activités professionnelles liées à l'industrie. Leur contribution à ce numéro de Téoros a donc à la fois la saveur de l'expérience et le goût du témoignage, ce qui en fait une contribution exceptionnelle pour mieux connaître cette réalité, telle que perçue de linterieur.

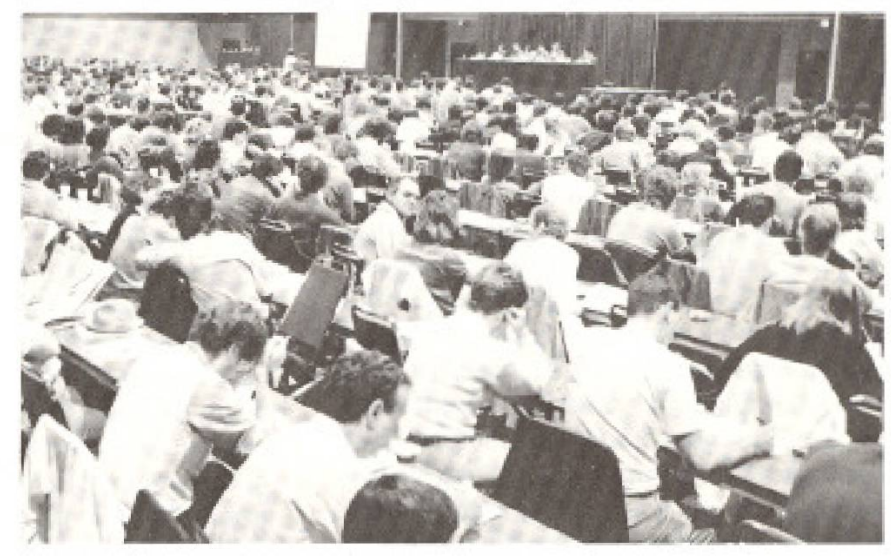

Chaque profession ou science a son discours, son vocabulaire réservé aux initiés. C'est pourquoi, dans un premier temps, nous vous invitons à discuter les notions "tourisme et congrès", à mémoriser le vocabulaire nécessaire à un dialogue intelligent et à connaître les gens et les types de destination qui offrent leurs services aux organisations de congrès.

Par la suite, nous vous convions à réfléchir sur notre potentiel et nos nouvelles ressources par rapport à nos forces et à nos faiblesses et, surtout, le rôle essentiel que chacun doit jouer pour que cette industrie se développe sainement et avec succès au Québec.

Dans un prochain numéro. Téoros publiera quelques articles sur l'industrie des salons/expositions et des voyages motivation/récompenses pour compléter ce tour d'horizon du tourisme d'affaires et de congrès au Québec. Bonne lecture.

Pierre Labrie

Commissaire à l'accueil

et au développement touristiques

CIDEM-Tourisme (Ville de Montréal) 